\title{
Evaluation of the $\mathrm{pH}$ of secretions in the hypopharynx during gynaecological laparoscopy. Is the use of a laryngeal mask airway safe?
}

\author{
Neiva Lemos J. ${ }^{1}$, Dantas de Pereira Cardoso H.E. ${ }^{1}$, Dantas Cardoso Neiva Lemos L. ${ }^{2}$, \\ Carvalho L.R. ${ }^{3}$, Pinheiro Módolo N.S. ${ }^{1}$
}

${ }^{1}$ Faculdade de Medicina de Botucatu, UNESP - Universidade Estadual Paulista, Department of Anaesthesiology, Botucatu, Brazil, ${ }^{2}$ Bahia School of Medicine and Public Health (EBMSP), Research and Development Department, Salvador, Brazil, ${ }^{3}$ School of Biosciences - UNESP, Botucatu, Brazil.

\section{Background and Goal of Study}

We evaluated the safety of using a ProSeal laryngeal mask airway during gynaecological laparoscopy, assessing the risk of regurgitation of gastric contentes by measuring the $\mathrm{pH}$ of secretions in the hypopharynx during the anaesthetic/surgical procedure.

\section{Materials and methods:}

In total, 80 patients were evaluated who were under general anaesthesia for gynaecological laparoscopy in which airway access was maintained using a ProSeal laryngeal mask airway. Secretions in the hypopharynx were collected by aspiration using an oesophageal drainage tube to measure their $\mathrm{pH}$ at various times during the anaesthetic/surgical procedure. We used $\mathrm{pH}$ test strips, pH 2-9 (Merck, Darmstadt, Germany), and in case of any doubts, a $\mathrm{pH}$ meter was also used. $\mathrm{A} \mathrm{pH}$ of $\leq 4.0$ was considered positive for the regurgitation of gastric contents.

\section{Results and discussion:}

None of the $\mathrm{pH}$ measurements of analysed secretions in the hypopharynx had a $\mathrm{pH}$ of $\leq 4.0$. The mean $\mathrm{pH}$ of the secretions varied from 6.34 for the lower means to 6.50 for the higher means when measured at different time points, which are comparable to the normal $\mathrm{pH}$ of saliva.

\section{References:}

1) Brain AIJ, Verghese C, Strube PJ. The LMA 'ProSeal' - a laryngeal mask with an oesophageal vent. Br J Anaesth 2005; 49: 275-80.

2) Cook TM, Lee G, Nolan JP. The ProsealTM laryngeal mask airway: a review of the literature. Can J Anaesth 2005; 52: 739-60.

3) Ambi U, Koppal R, Joshi C, Prakashappa DS, Iyer H. LMA Classic and LMA Proseal: a comparative study in paralyzed anaesthetized patients. J Clin Diagn Res 2011; 5: 940-3.
Table 1. Median and 1st and 3rd quartiles in brackets for different variables, according to the patients'ASA classification. The times are given in minutes.

\begin{tabular}{lccc}
\hline & \multicolumn{2}{c}{ ASA } & valor de \\
\cline { 2 - 4 } Variable & $\mathrm{I}(\mathrm{n}=64)$ & $\mathrm{N}(\mathrm{n}=16)$ & $\mathrm{p}$ \\
\hline Fasting time & $657,5[517,5 ; 800,0]$ & $615,0[573,5 ; 712,5]$ & 0,87 \\
Anaesthesia time & $101,0[87,0 ; 120,0]$ & $110,0[95,0 ; 127,5]$ & 0,27 \\
Surgery time & $58,0[47,5 ; 80,0]$ & $69,0[55,5 ; 88,0]$ & 0,13 \\
Pneumoperitonium time & $38,0[28,0 ; 55,0]$ & $42,5[35,5 ; 54,0]$ & 0,32 \\
Head-down time & $34,0[24,0 ; 47,5]$ & $38,0[33,5 ; 45,5]$ & 0,31
\end{tabular}

There were no statistically significant differences between variables depending on the patients' ASA classification.

Fig. 1. Mean values of the $\mathrm{pH}$ according to the stage of surgery.

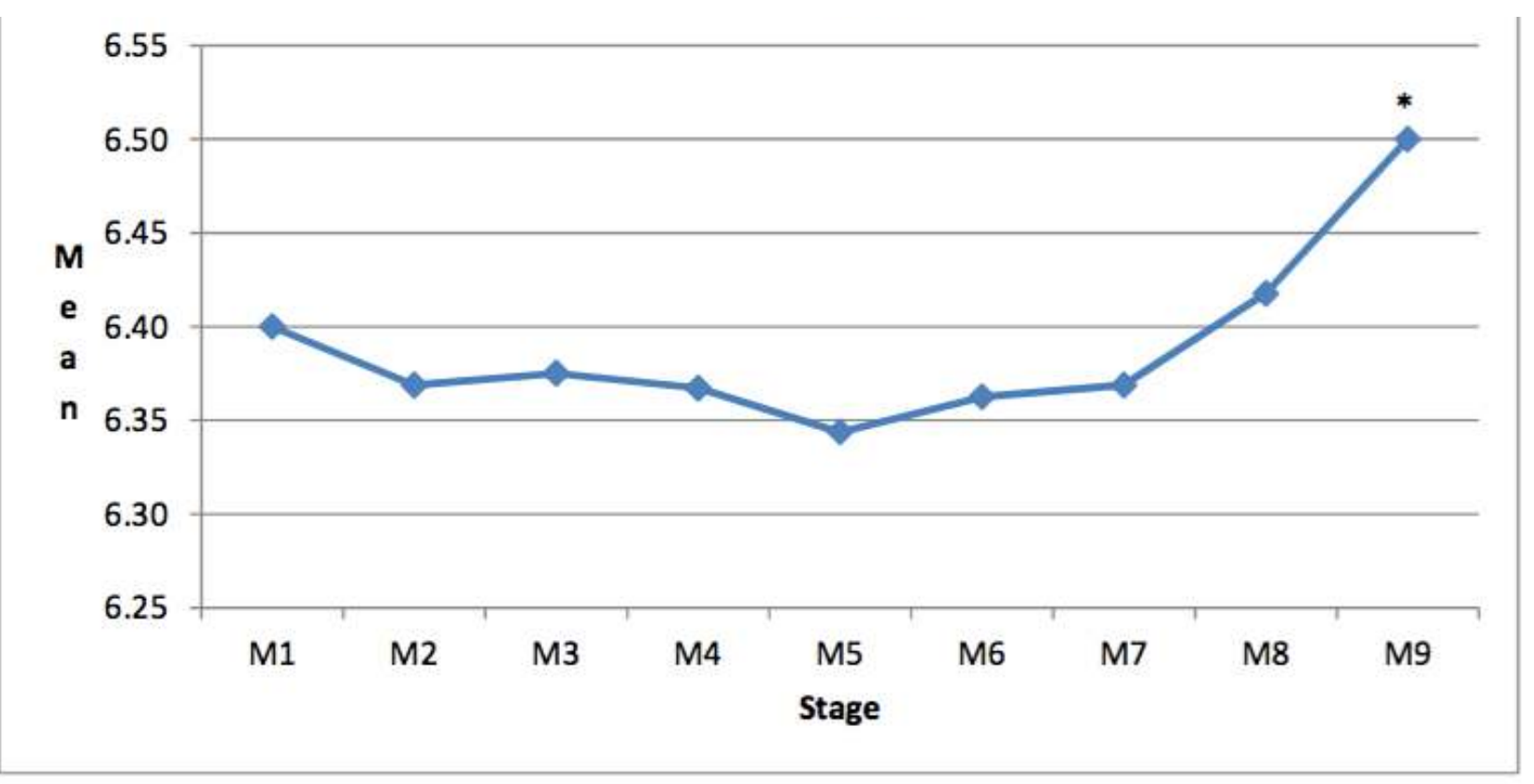

* M9 is significantly different from the other stages.

\section{Conclusion(s):}

From these results, we conclude that the ProSeal laryngeal mask airway is a safe alternative for anaesthesia during laparoscopic surgery for patients without risk factors for the regurgitation of gastric contents. 